\title{
Electrochemical Characterization of Aromatic Molecules with 1,4-Diaza Groups for Flow Battery Applications
}

Pasadakis-Kavounis, Alexandros; Baj, Vanessa; Hjelm, Johan

Published in:

Molecules

Link to article, DOI:

$10.3390 /$ molecules26082227

Publication date:

2021

Document Version

Publisher's PDF, also known as Version of record

Link back to DTU Orbit

Citation (APA):

Pasadakis-Kavounis, A., Baj, V., \& Hjelm, J. (2021). Electrochemical Characterization of Aromatic Molecules with 1,4-Diaza Groups for Flow Battery Applications. Molecules, 26(8), [2227].

https://doi.org/10.3390/molecules26082227

\section{General rights}

Copyright and moral rights for the publications made accessible in the public portal are retained by the authors and/or other copyright owners and it is a condition of accessing publications that users recognise and abide by the legal requirements associated with these rights.

- Users may download and print one copy of any publication from the public portal for the purpose of private study or research.

- You may not further distribute the material or use it for any profit-making activity or commercial gain

- You may freely distribute the URL identifying the publication in the public portal 


\title{
Article \\ Electrochemical Characterization of Aromatic Molecules with 1,4-Diaza Groups for Flow Battery Applications
}

\author{
Alexandros Pasadakis-Kavounis (D), Vanessa Baj (D) and Johan Hjelm *(D) \\ Department of Energy Conversion and Storage, Technical University of Denmark, 2800 Kgs. Lyngby, Denmark; \\ alpaka@dtu.dk (A.P.-K.); vanbaj@dtu.dk (V.B.) \\ * Correspondence: johh@dtu.dk
}

Citation: Pasadakis-Kavounis, A.; Baj, V.; Hjelm, J. Electrochemical

Characterization of Aromatic

Molecules with 1,4-Diaza Groups for Flow Battery Applications. Molecules 2021, 26, 2227. https://doi.org/ $10.3390 /$ molecules 26082227

Academic Editors: Joanna Krakowiak Petr Mazur and Peter Fischer

Received: 8 March 2021

Accepted: 6 April 2021

Published: 12 April 2021

Publisher's Note: MDPI stays neutral with regard to jurisdictional claims in published maps and institutional affiliations.

Copyright: (c) 2021 by the authors. Licensee MDPI, Basel, Switzerland This article is an open access article distributed under the terms and conditions of the Creative Commons Attribution (CC BY) license (https:// creativecommons.org/licenses/by/ $4.0 /)$.

\begin{abstract}
The aqueous redox flow battery is a promising technology for large-scale low cost energy storage. The rich possibilities for the tailoring of organic molecules and the possibility to discover active materials of lower cost and decreased environmental impact continue to drive research and development of organic compounds suitable for redox flow battery applications. In this work, we focus on the characterization of aromatic molecules with 1,4-diaza groups for flow battery applications. We examine the influence of electron-withdrawing and electron-donating substituents and the effect of the relative position of the substituent(s) on the molecule. We found that electronwithdrawing substituents increased the potential, while electron-donating decreased it, in agreement with expectations. The number of carboxy-groups on the pyrazinic ring was found to have a strong impact on the heterogeneous electron transfer kinetics, with the slowest kinetics observed for pyrazine-2,3,5,6-tetracarboxylic acid. The stability of quinoxaline was investigated by cyclic voltammetry and in a flow cell configuration. Substitution at the 2,3-positions in quinoxaline was found to decrease the capacity fade rate significantly. Furthermore, we demonstrated how molecular aggregation reduces the effective number of electrons involved in the redox process for quinoxalines. This translates to a significant reduction of the achievable volumetric capacity at higher concentrations, yielding values significantly lower than the theoretical capacity. Finally, we demonstrate that such capacity-limiting molecular aggregation may be reduced by introducing flexible side chains with bulky charged groups in order to increase electrostatic repulsion and steric hindrance.
\end{abstract}

Keywords: aqueous organic flow batteries; materials; electrochemistry; NMR

\section{Introduction}

The rapid increase in installed capacity of intermittent renewable energy sources motivates research into sustainable and low cost stationary energy storage technologies. Redox flow batteries (RFBs) are particularly attractive for large-scale energy storage due to the decoupled power and energy inherent in such systems, and the resulting falling cost of energy storage with increasing discharge times. Aqueous organic flow batteries are particularly attractive for large-scale energy storage due to the use of a non-flammable electrolyte and the promise of environmentally-benign components. Mass production costs of the active materials and electrolyte lifetime are the primary barriers for widespread introduction of commercial aqueous organic flow batteries. It has been projected that large scale production of organic active materials for flow batteries can have low production costs [1] but requires relatively few synthetic steps and low cost raw materials [2,3].

Organic molecules offer high tailorability through structural modification using a large variety of functional groups and substitutions. This way, high solubility, suitably placed redox potentials, fast charge transfer kinetics, and chemical stabilities in the order of decades may be achieved [4]. The most common groups of organic molecules studied for aqueous RFB applications include quinones [1,2,5-7] and $N$-containing organic heterocycles, such as phthalazine [7], quinoxaline [8], and phenazine [9-12]. 
Both pyrazine and quinoxaline are stable aromatic compounds containing two nitrogen atoms in the ring. The lone pairs located on the nitrogen atoms are not delocalized in the aromatic ring and therefore provide a nucleophilic character to the molecule, and a weak basicity (pKa of the conjugate acid in the range 0.60-0.88). Furthermore, in contrast to the energy of the $p$ orbitals in benzene, $N$-containing aromatic molecules have lower energy orbitals as a result of the greater electronegativity of the nitrogen atom compared to that of carbon. Lower-energy filled $p$ orbitals make the molecule less prone to react with nucleophiles but more reactive towards electrophiles [13]. The electrochemical reduction of pyrazine and quinoxaline is characterized by the transfer of two electrons to yield their 1,4-dihydro-counterparts with a varying number of protons involved depending on the $\mathrm{pH}$ of the solution $[14,15]$.

\subsection{Pyrazine}

The simplest $\mathrm{N}$-containing aromatic compound presented in this study is pyrazine $\mathbf{1}$. Pyrazine 1 undergoes reduction to give 1,4-dihydropyrazine 1a through a coupled two electron, three proton transfer reaction (Figure 1). In cyclic voltammetry, at acidic $\mathrm{pH}(<2)$ the two individual one-electron transfer processes are visible as two separated peaks, while the two peaks coalesce into a single peak at higher $\mathrm{pH}$ [14]. Swartz and Anson performed a series of staircase voltammetric and polarographic measurements of substituted pyrazines (1-5) at $\mathrm{pH} 1$ in a $0.1 \mathrm{M}$ perchlorate electrolyte [16]. Under those conditions, the total number of protons and electrons involved were three and two, respectively, for all the substituted pyrazines; the reversibility of the different compounds was affected by the $\mathrm{pH}$ and the scan rate used. Electron-withdrawing groups such as in molecules 2 and 3 tended to increase stability and shift the redox potential to more positive values, while electron-donating groups (pyrazines 4 and 5) showed the opposite behavior [16]. Reduced pyrazine 1 undergoes decomposition in aqueous solution that is acid-base catalyzed with the slowest decomposition rate at $\mathrm{pH} \sim 3$ [14].

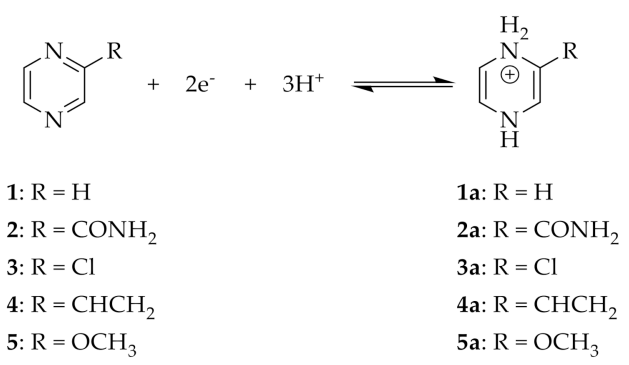

Figure 1. Chemical structures of the different pyrazines studied by Swartz and Anson [16] and the general reduction scheme.

\subsection{Quinoxaline}

Quinoxaline (QUI) 6 is an $N$-containing heterocyclic compound made up of a pyrazine ring fused with a benzene ring. The redox potential is more positive relative to that of pyrazine 1 due to the presence of the second aromatic ring [16]. Similar to pyrazine, the total number of electrons involved in the reduction reaction (6 to 7, first step, Figure 2 ) has been postulated to be two [8], while the number of protons depends on the chemical environment and most notably on the $\mathrm{pH}$ of the electrolyte solution $[8,15,17]$. Additionally, the $\mathrm{pH}$ has a significant influence on the stability of the reduced form 7 , as well as the reversibility of the oxidation/reduction process. The reduced form of quinoxaline 7 in mild to acidic $\mathrm{pH}$ can have two possible degradation mechanisms. In degradation mechanism a, quinoxaline 7 undergoes a Michael addition of a molecule of $\mathrm{H}_{2} \mathrm{O}$ to give molecule 8a, which is thought to be immediately converted to the non-redox active tautomer 9a $[8,15]$, whereas the other possible pathway includes a catalytic addition of a proton to molecules $\mathbf{8 b}$. Hereafter, molecule $\mathbf{8 b}$ tautomerizes to $\mathbf{9 b}$, which is then irreversibly reduced to nonredox active molecule $\mathbf{1 0 b}$ [18]. The former is visible in cyclic voltammetry as an additional 
oxidation peak at a more positive potential relative to that shown by its redox potential [15]. A study of the electrochemistry of QUI 6 dissolved in different electrolytes revealed that the presence of at least $10 \mathrm{mM} \mathrm{OH}^{-}$(regardless of the cation counter-ion) $(\mathrm{pH}>11)$ improved cycling stability and reversibility [8].<smiles>c1ccc2nccnc2c1</smiles>

6

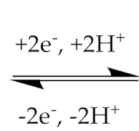

$-2 \mathrm{e},-2 \mathrm{H}$

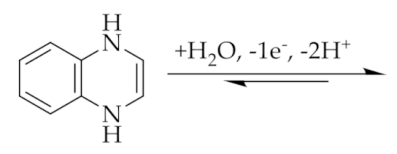

7 cat. H+

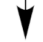<smiles>C1=CNc2ccccc2N1</smiles>

$8 \mathrm{~b}$<smiles>OC1=CNc2ccccc2N1</smiles>

$8 \mathrm{a}$<smiles>C1=Nc2ccccc2NC1</smiles>

$9 b$<smiles>O=C1CNc2ccccc2N1</smiles>

9a

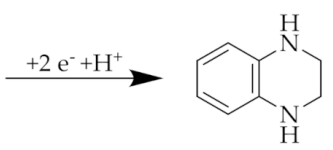

$10 \mathrm{~b}$

Figure 2. Degradation mechanism of quinoxaline (QUI) 6 in acidic to neutral conditions. (a) Formation of quinoxalin-2-ol and/or 1,2,3,4-tetrahydroquinoxaline-2-one [15]. (b) Formation of 1,2,3,4tetrahydroquinoxaline [18].

QUI 6 shows some promising features for utilization as a negolyte in an alkaline redox flow battery. The estimated solubility in $>0.9 \mathrm{M} \mathrm{KCl}$ electrolyte was reported to be $4 \mathrm{M}$ [8]. The relatively low redox potential of pyrazine and quinoxaline is an attractive feature for a flow battery negolyte, but the limited stability of the reduced state of these molecules is a critical barrier to the utilization of these materials for energy storage. In this study we set out to investigate the properties of a set of pyrazine and quinoxaline derivatives to shed light on the effect of different functional groups, $\mathrm{pH}$, and substitution patterns on critical parameters, such as redox potential, electrochemical kinetics, and molecular stability.

\section{Results}

\subsection{Substituted Pyrazines}

The introduction of functional group alters the physicochemical and electrochemical properties of pristine pyrazine [16]. The type and number of substituents play major roles in the response [19]. Herein, methyl and carboxylic acid groups were chosen as electron-donating and electron-withdrawing groups, respectively. The effect of the nature and the number of substituents on the pyrazine ring was studied by cyclic voltammetry. The structures of six of the investigated pyrazines are shown in Figure 3. It consists of pristine pyrazine $(\mathbf{1})$ and mono- $(\mathbf{1 0 , 1 3})$, di- $(\mathbf{1 1}, \mathbf{1 4})$, and tetra-substituted $(\mathbf{1 2}, \mathbf{1 5})$ pyrazines with methyl and carboxylic acid substituents.<smiles>Cc1cnccn1</smiles>

10<smiles>O=C(O)c1cnccn1</smiles><smiles>Cc1cnc(C)cn1</smiles>

11<smiles>Cc1nc(C)c(C)nc1C</smiles>

12<smiles>O=C(O)c1nc(C(=O)O)c(C(=O)O)nc1C(=O)O</smiles>

Figure 3. Chemical structures of the different pyrazines studied. 
A $5 \mathrm{mM}$ solution of each analyte in $0.1 \mathrm{M} \mathrm{KOH} / 0.9 \mathrm{M} \mathrm{KCl}$ was prepared and analyzed using voltammetry. Based on the shape of the voltammograms (Figure 4), it was clearly visible that the reversibility of the redox couple was reduced, with increasing number of substituents present, for both types of substituents. This effect was especially pronounced in pyrazine-2,3,5,6-tetracarboxylic acid 15, where the peak separation grew to almost $2 \mathrm{~V}$, indicating very slow electrochemical kinetics. There are several factors that could affect the electrochemical kinetics and cause the large peak separation; these include steric hindrance, electrostatic factors, hydrogen bonding, intra-molecular effects, and structural reorganization [20-22]. In the methyl-substituted pyrazines (10-12), both the anodic and the cathodic peak were shifted negatively by similar values, indicating that the methyl group only affected the energy level of the pyrazine ring and not its kinetic behavior, since the separation of the two peaks remained the same. The average peak potential dropped by approximately $55 \mathrm{mV}$ per methyl group, similar to the $50 \mathrm{mV}$ reported by Swartz et al. in phosphate citrate buffers at $\mathrm{pH}<2$ [16]. The expected behavior from an electronwithdrawing group would be to shift the potential to more positive values [16]. This clearly applied to the mono-substituted carboxylic acid pyrazine 13, wherein both oxidation and reduction peak shifted in the predicted direction. In contrast, in more densely-substituted pyrazines 14 and 15 the heterogeneous kinetics were affected with a dramatic increase in the peak split, indicating a much reduced electron transfer rate, obscuring substituent effects on the redox potential to some extent. Nevertheless a small increase in the redox potential with increasing number of substituents was detected for the carboxy-pyrazines (13-15) (slope $=+44 \mathrm{mV}$ per carboxy-group, see inset in Figure $4 \mathrm{~b}$ ).
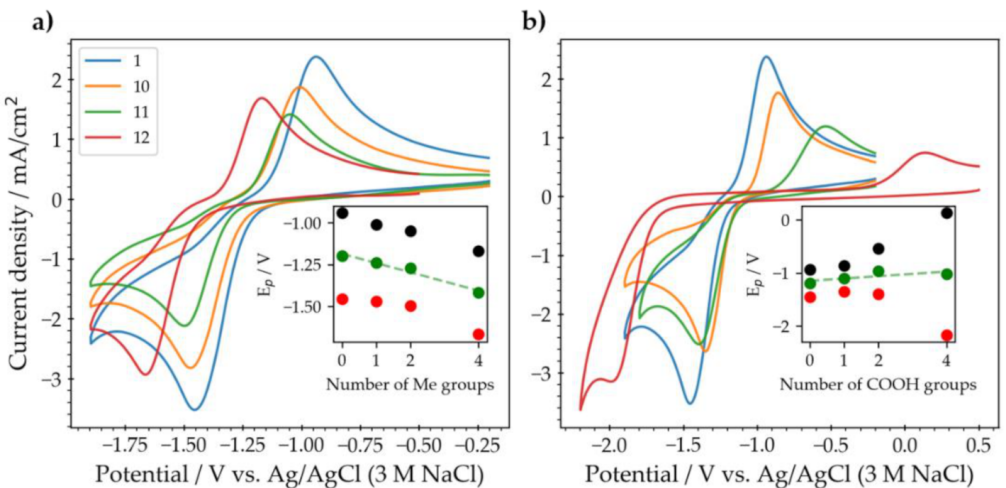

Figure 4. (a) Cyclic voltammetry of pyrazine $\mathbf{1}$ (blue), and mono- $\mathbf{1 0}$ (orange), di- $\mathbf{1 1}$ (green), and tetra-methyl 12 (red)-substituted pyrazine. (b) Cyclic voltammetry of pyrazine $\mathbf{1}$ (blue) and mono13 (orange), di-14 (green), and tetra-pyrazine-carboxylic acid 15 (red). The black, red, and green circles on the inset graphs correspond to the oxidation, reduction, and average peak potential of each different pyrazine as a function of the number of functional groups. The concentration of each analyte was $5 \mathrm{mM}$ in $0.1 \mathrm{M} \mathrm{KOH} / 0.9 \mathrm{M} \mathrm{KCl}$. The voltammograms were recorded at a scan rate of $250 \mathrm{mV} / \mathrm{s}$ using a $3 \mathrm{~mm}$ diameter glassy carbon disk electrode.

\subsection{Substituted Quinoxalines in Unbuffered Conditions}

The potential of pyrazine $\mathbf{1}$ (and its derivatives 10-15) is well past the thermodynamic hydrogen evolution limit and close to the kinetic hydrogen evolution limit. That is a possible obstacle for use in a RFB system for both safety issues and loss of efficiency. Therefore, a representative system of six differently-substituted quinoxalines (Figure 5) was investigated in the same way as for pyrazines with a special focus on the effect of different functional groups. 


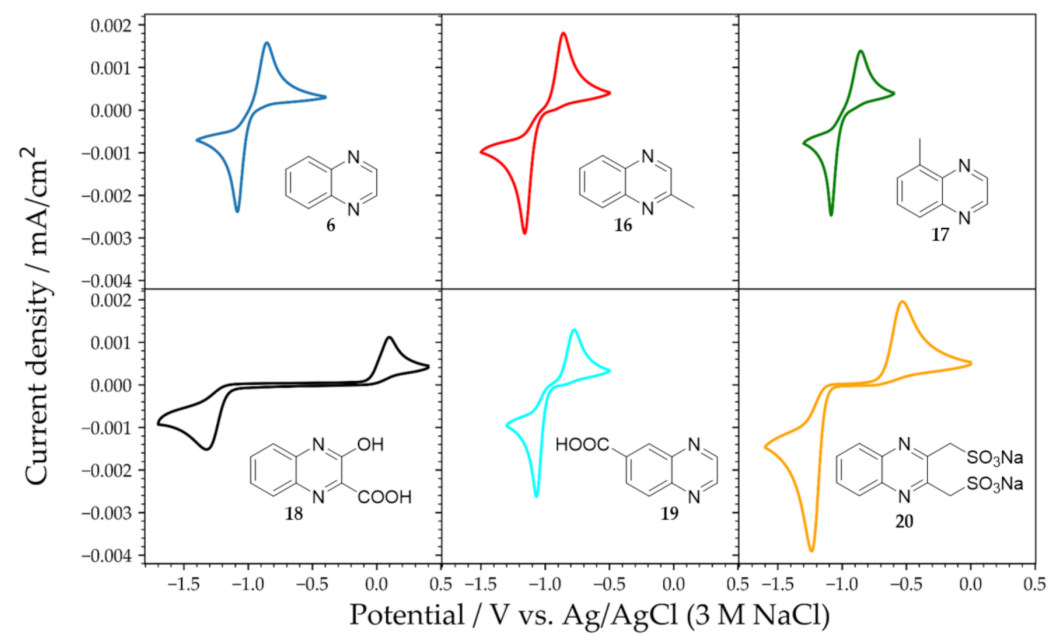

Figure 5. Cyclic voltammetry of $5 \mathrm{mM}$ solutions of quinoxalines 6, 16-20 dissolved in $0.1 \mathrm{M}$ $\mathrm{KOH} / 0.9 \mathrm{M} \mathrm{KCl}$. The voltammograms were recorded at a scan rate of $100 \mathrm{mV} / \mathrm{s}$ using a $3 \mathrm{~mm}$ diameter glassy carbon disk electrode.

Figure 5 illustrates the resulting voltammograms of solutions of $5 \mathrm{mM}$ analyte dissolved in $0.1 \mathrm{M} \mathrm{KOH} / 0.9 \mathrm{M} \mathrm{KCl}$. The kinetics and the redox potential were affected both by the type and the position (relative to the active ring) of the functional groups. Molecules 20 and $\mathbf{1 8}$ have charged functional groups attached to the pyrazine ring and displayed the slowest electrochemical kinetics. When similar groups (e.g., $-\mathrm{COOH}$ ) were attached further away from the pyrazine ring, it had a significantly smaller effect on the kinetics (19).

Closer inspection of the observed average peak potentials (Table 1) shows that the influence of a functional group on the redox potential depends on its relative position to the quinoxaline core. For example, the measured average peak potential of 2-methyl quinoxaline $\mathbf{1 6}$ was $40 \mathrm{mV}$ more negative than the one of 5-methyl quinoxaline $\mathbf{1 7}$.

Table 1. Average peak potential of $5 \mathrm{mM}$ solutions of quinoxalines 6, 16-20 dissolved in $0.1 \mathrm{M}$ $\mathrm{KOH} / 0.9 \mathrm{M} \mathrm{KCl}$. All potentials are given versus the $\mathrm{Ag} / \mathrm{AgCl}(3 \mathrm{M} \mathrm{NaCl})$ reference electrode.

\begin{tabular}{cc}
\hline Compound & $\begin{array}{c}\text { Average Peak Potential (V) } \\
\text { Vs. Ag/AgCl (3 M NaCl) }\end{array}$ \\
\hline Quinoxaline (QUI) 6 & -0.970 \\
2-Methylquinoxaline 16 & -1.012 \\
5-Methylquinoxaline 17 & -0.972 \\
2-Hydroxyquinoxaline-3-carboxylic acid 18 & -0.458 \\
Quinoxaline-6-carboxylic acid 19 & -0.923 \\
Sodium & -0.890 \\
quinoxaline-2,3-diyldimethanesulfonate \\
(DSMeQUI) 20
\end{tabular}

QUI 6 was further studied in unbuffered electrolyte solutions from $\mathrm{pH} 3.5$ to about 13.5 (Figure 6). At $\mathrm{pH} \mathrm{11}$, the average peak potential slope was equal to $44 \mathrm{mV} / \mathrm{pH}$ corresponding to 4 electrons and 3 protons, or 2 electrons and 1.5 protons. As shown from previous studies, the total number of electrons involved at low concentrations of QUI 6 is around two [8]. The slopes of the peak reduction and oxidation potential vs. $\mathrm{pH}$ differed significantly, 25 and $63 \mathrm{mV} / \mathrm{pH}$, respectively, indicating that the number of protons involved in the two processes are different. The slope of the reduction potential vs. $\mathrm{pH}$ was close to $29.5 \mathrm{mV} / \mathrm{pH}$, which corresponds to two electrons and one proton, while for the oxidation it was close to $59 \mathrm{mV} / \mathrm{pH}$ corresponding to an equal number of electrons and protons involved, in this case two electrons and two protons. 
a)

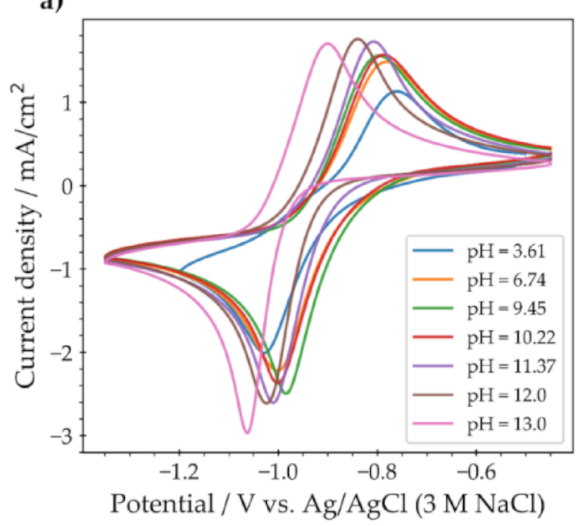

b)

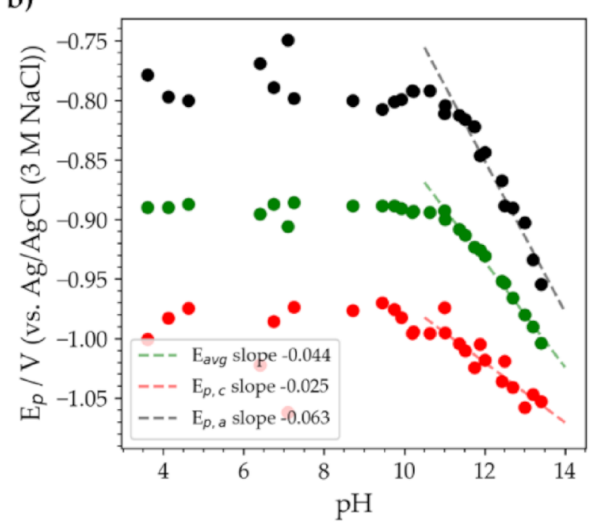

Figure 6. (a) Cyclic voltammograms of a $5 \mathrm{mM}$ solution of QUI 6 in unbuffered solution of $1 \mathrm{M} \mathrm{KCl}$ at different pHs. (b) The resulting potential-pH diagram shows the reduction (red), average (green), and oxidation (black) peak potentials. The voltammograms were recorded at a scan rate of $100 \mathrm{mV} / \mathrm{s}$ using a $3 \mathrm{~mm}$ diameter glassy carbon disk electrode.

\subsection{QUI 6 and DSMeQUI 20 in Buffered Solutions}

In the absence of buffer, the proton coupled reduction process of QUI 6 to 7 causes an increase in the $\mathrm{pH}$ close to the electrode surface due to the removal of protons from the solution. The electrochemical behavior of QUI 6 was also examined in buffered solutions where the $\mathrm{pH}$ was practically constant [6]. Britton-Robinson universal buffer solution was used due to the wide range of $\mathrm{pH}$ available (2-12), alongside the ease of tuning the $\mathrm{pH}$ to the desired value by adding $\mathrm{KOH}$ without changing the substrate.

The response of QUI 6 in buffered solutions is depicted in Figure 7. Below $\mathrm{pH}=$ 9 , a second oxidation peak was visible and it increased in size as the $\mathrm{pH}$ decreased. It corresponds to the oxidation of dihydroquinoxaline (7) to yield the hydroxyl derivative 8a, which then may tautomerize to $\mathbf{9 a}$ (8a to $\mathbf{9 a}$, Figure 2) [15]. The degradation process to form $8 \mathbf{a}$ was less pronounced in unbuffered solutions, likely due to the local increase of the $\mathrm{pH}$ (near the electrode surface) caused by the reduction of QUI 6. The appearance of multiple peaks at $\mathrm{pH}=1.7$ was likely due to a combination of different reasons. The oxidation and reduction peaks split into two separate one-electron peaks at low $\mathrm{pH}$ [6]. Additionally, QUI 6 may undergo irreversible electrochemically driven degradation reactions at positive potentials (Figure 2), likely explaining the most positive observed small oxidation peak.

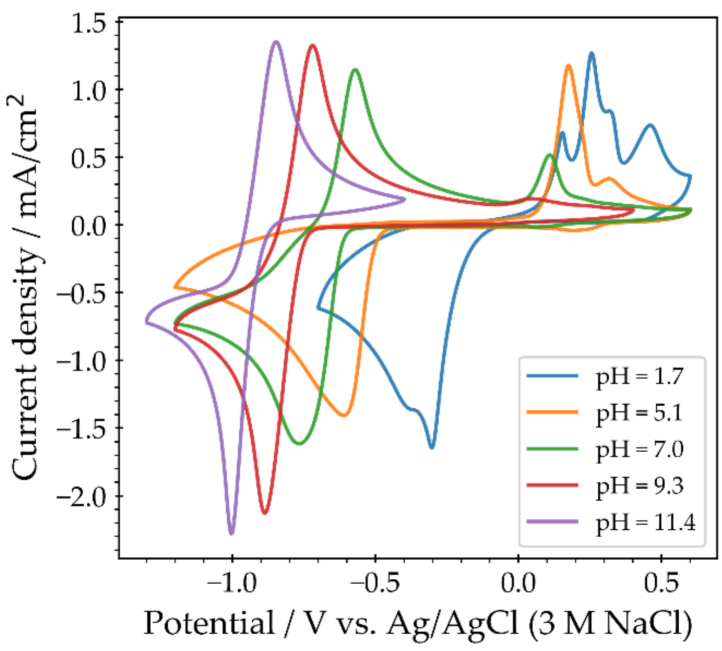

Figure 7. Cyclic voltammetry of pristine quinoxaline on GC in a Britton-Robinson universal buffer solution with added $\mathrm{KCl}$. The $\mathrm{pH}$ ranged from 1.7 to 11.4. The voltammograms were recorded at a scan rate of $100 \mathrm{mV} / \mathrm{s}$ using a $3 \mathrm{~mm}$ diameter glassy carbon disk electrode. 
DSMeQUI 20 was also studied at various pHs in buffered electrolyte solutions. The substituents in the 2,3 positions hinders $\mathrm{OH}$ addition, and therefore the second oxidation peak, thought to correspond to the $\mathrm{OH}$ addition was not observed. DSMeQUI 20 appeared to have the fastest kinetics among all the substituted quinoxalines at $\mathrm{pH}=3$, as indicated by the small peak separation (red and black points on Figure $8 \mathrm{~b}$ ). At low $\mathrm{pH}$ values, multiple redox waves were visible both for QUI 6 and for DSMeQUI 20, likely due to potential inversion, i.e., when the order of the two one-electron processes changed, resulting in separate peaks. Similar behavior was observed in pyrazine [14,16].
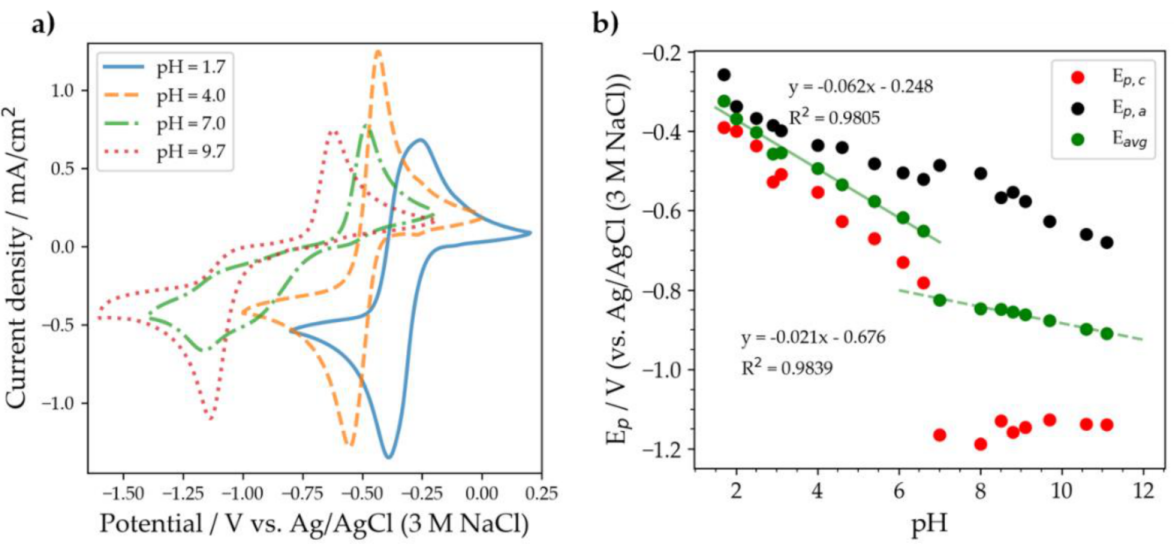

Figure 8. (a) Cyclic voltammetry of a $5 \mathrm{mM}$ DSMeQUI 20 solution in a Britton-Robinson universal buffer solution with added $\mathrm{KCl}$ at various $\mathrm{pHs}$. The voltammograms were recorded at a scan rate of $100 \mathrm{mV} / \mathrm{s}$ using a $3 \mathrm{~mm}$ diameter glassy carbon disk electrode. (b) The reduction (red) and oxidation (black) peak potential and average peak potential (green) as a function of $\mathrm{pH}$.

The blue lines in Figure 9 depict the first two cycles of the cyclic voltammetry of QUI 6 at $\mathrm{pH}=4.5$. Depicted in orange is the voltammogram of DSMeQUI 20 at $\mathrm{pH}=2.5$. Already in the second scan of the QUI 6 solution, a reduction of the peak current was observed, indicating significant degradation of QUI 6 to the electro-inactive compound 9a. Despite the $\mathrm{pH}$ being lower in the DSMeQUI 20 solution, no second oxidation peak was observed, and the peak current was unchanged over several scans. This indicates that the degradation reaction was not taking place in this molecule, at least not on the experimental time-scale employed here. The increased stability of DSMeQUI 20 in comparison to QUI 6 was also evident in their charge-discharge curves (Supplementary Materials, Figures S8 and S9). QUI 6 could be cycled five times at $\mathrm{pH} 13$ before most of the capacity was lost. In contrast, DSMeQUI 20 could be cycled at least 110 times before most of the capacity was lost at the same $\mathrm{pH}$. The solution of QUI 6 after five cycles was analyzed by LC-MS (Supporting Info., Figure S10). It revealed the formation of two new compounds with masses of $146.86 \mathrm{gmol}^{-1}$ and $134.84 \mathrm{gmol}^{-1}$, corresponding to the oxidized form of $\mathbf{8 a}$ and $\mathbf{1 0 b}$, respectively, supporting the two hypothesized degradation pathways. However, detection of $8 \mathbf{a}$ contradicts the idea that it is immediately converted to its non-redox active tautomer (9a). QUI 6 was still present as a major component in the solution based on LCMS analysis. This indicates that chemical degradation of QUI 6 was not the main reason for the observed capacity fade. No leakage was detected, and no volumetric imbalance in the two tanks was observed. The fast capacity fade may related to other factors, such as crossover and/or gas evolution. A quantitative ${ }^{1} \mathrm{H}-\mathrm{NMR}$ of pristine and post-test QUI 6 electrolyte confirms that QUI 6 is the main component in the post test electrolyte, but also that approximately half of the QUI 6 was lost during testing, indicating that cross-over constitutes a large part of the capacity fade for this molecule. Detailed information on the flow cell battery test conditions are given in Section 2.4. 


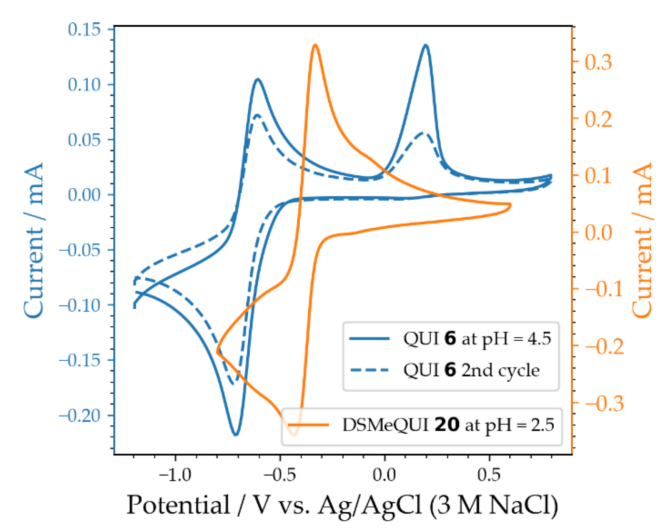

Figure 9. Cyclic voltammetry of $5 \mathrm{mM}$ QUI 6 (blues) and $5 \mathrm{mM}$ DSMeQUI 20 (orange) solutions in Britton-Robinson buffer adjusted to $\mathrm{pH} 4.5$ and $\mathrm{pH}=2.5$, respectively. The voltammograms were recorded at a scan rate of $100 \mathrm{mV} / \mathrm{s}$ using a $3 \mathrm{~mm}$ diameter glassy carbon disk electrode.

\subsection{Concentration Dependent Response}

A $0.1 \mathrm{M}$ DSMeQUI 20 (or QUI 6) solution in $0.1 \mathrm{M} \mathrm{KOH} / 2 \mathrm{M} \mathrm{KCl}$ (anolyte) was inserted in a flow battery single cell and paired with $0.2 \mathrm{M}$ of ferrocyanide and $0.2 \mathrm{M}$ ferricyanide (posolyte). Excess capacity of the posolyte was used to make the negolyte the capacity limiting side, as we were interested in the behavior of the negolyte [22]. Carbon cloth (ELAT-H) was used as electrodes and mPBI (10 $\mu \mathrm{m}$ thickness) as a membrane to separate the cathode from the anode. The electrodes were heated for $24 \mathrm{~h}$ at $400{ }^{\circ} \mathrm{C}$ in air prior to test. A loss of approximately $20 \%$ capacity was observed immediately from the first cycle (Supporting Info., Figure S8). The negolyte solution was examined by ${ }^{1} \mathrm{H}-\mathrm{NMR}$ and compared with the pristine solution of DSMeQUI 20 (Supporting Info., Figure S1). A new set of peaks arose in the aromatic region, showing the presence of an additional molecule, which could be a degradation product or DSMeQUI 20 in a different protonation state. The integration of the detected new peaks in the NMR spectrum did not completely match a $20 \%$ loss in capacity but indicated that the new product corresponds to about $16 \%$ and the remainder (84\%) was DSMeQUI 20. A study of dimerization of anthraquinonedisulfonate (2,7-AQDS) presented by Carney et al. [23] showed that aggregation (dimerization) could reduce the effective number electrons of the redox reaction. A non-integer effective number of electrons involved in the QUI 6 redox reaction was reported in a voltammetric investigation by Milshtein et al. [8]. In order to obtain an indication of whether the discrepancy between the theoretical and the observed initial cycle capacity may be related to molecular aggregation, we examined the concentration dependence of the peak currents observed in cyclic voltammetry of DSMeQUI 20. The peak current density observed in cyclic voltammetry depends on the number of electrons involved, the concentration, and on the diffusion coefficient of the species [24]. A series of cyclic voltammetry measurements were therefore conducted at concentrations of DSMeQUI 20 from 1 to $250 \mathrm{mM}$ (Supporting Info., Figure S7). A drop of the concentration (C) and the scan rate $(v)$ normalized cathodic peak current $\left(\mathrm{I}_{\mathrm{p}} /\left(v^{1 / 2} \mathrm{C}\right)\right)$ with increasing concentration was observed and indicated that the effective number of electrons decreased with increasing concentration. The same experiments conducted on QUI 6 indicated that the number of electrons involved in the redox reaction also decreased with increasing concentration. Owing to this complication, we were not able to determine the diffusion coefficient and the effective number of electrons via cyclic voltammetry, as we had one unknown too many. Instead, we utilized low-field NMR spectroscopy to investigate the possible aggregation of QUI 6 (Supporting Info., Figure S2) and DSMeQUI 20 (Figure 10). 
a)
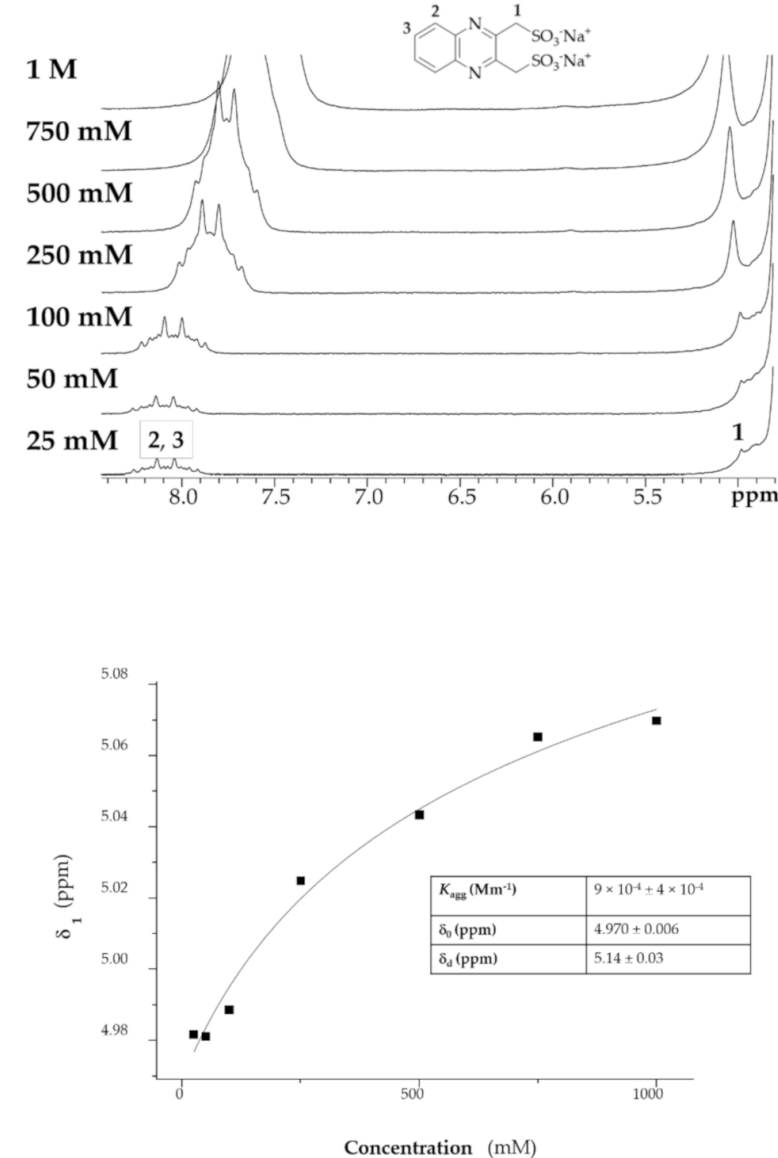

Figure 10. (a) ${ }^{1} \mathrm{H}-\mathrm{NMR}$ spectra with increasing concentration of DSMeQUI 20. (b) Non-linear least squares fitting using the Horman and Dreux model to determine the aggregation constant of DSMeQUI 20.

Concentration dependent peak shifts observed in NMR spectra were monitored in order to gain more information regarding the aggregation constant and the structure (dimers, trimers, etc.) of the possible aggregates. ${ }^{1} \mathrm{H}-\mathrm{NMR}$ spectra at different concentration of DSMeQUI 20 (from $1 \mathrm{M}$ to $25 \mathrm{mM}$ in the $0.1 \mathrm{M} \mathrm{KOH} / 0.9 \mathrm{M} \mathrm{KCl}$ ) were recorded. As shown in Figure 10a, with increasing concentrations of the analyte, there was a shift of the aromatic signals toward lower fields and of the $\mathrm{CH}_{2}$ connected to the sulfonates group to higher fields. This is indicative of a fast equilibrium between the monomer and the aggregate structure(s) formed by a $\pi$-stacking interaction.

The different $\delta$ at the various concentrations for both signals 2,3 and 1 were noted and fitted using both the dimer model for aggregation from Horman and Dreux [25] and the isodesmic model [23] (equations described in the Supporting Info., Figure S2 and one fitting example is shown in Figure 10b). The model of Horman and Dreux assumes that only dimerization takes place, while the isodesmic model takes into account all the possible poly-aggregates. The same titration was performed also with QUI 6 as analyte to understand the effect of the sulfonate groups on this phenomenon. Additionally, a positively charged trimethylammonium quinoxaline 21 (DNMeQUI) was synthesized and analyzed in the same way to confirm to what extent the aggregation was hindered by electrostatic repulsion (Supplementary Materials, Figure S3). The obtained best-fit values after fitting the two models to the data are tabulated below (Table 2). 
Table 2. Aggregation constants of the three molecules investigated (QUI 6, DSMeQUI 20, and DNMeQUI 21). Both the Horman and Dreux and isodesmic models were used (Supporting Info., Figures S4-S6).

\begin{tabular}{ccc}
\hline Molecule & $\begin{array}{c}\text { Kagg }\left(\mathbf{m M}^{-1}\right) \\
\text { Horman and Dreux Model }\end{array}$ & $\begin{array}{c}\text { Kagg (mM-1) } \\
\text { Isodesmic Model }\end{array}$ \\
\hline QUI 6 & $2.68( \pm 1.58)$ & $2.73( \pm 1.21)$ \\
DSMeQUI 20 & $0.56( \pm 0.32)$ & $0.73( \pm 0.35)$ \\
DNMeQUI 21 & $0.08( \pm 0.1)$ & $0.09( \pm 0.14)$ \\
\hline
\end{tabular}

The obtained aggregation constants (Supporting Info., Figures S4-S6) using the two different models were almost identical, indicating that the dominating aggregate formed was a dimer, and that any higher aggregates were only present at very low concentration. The bulky and charged side groups reduced dimerization likely due to both steric hindrance effects and coulombic repulsion.

The actual concentration of both monomer $\left(\mathrm{C}_{\text {monomer }}\right)$ and dimer $\left(\mathrm{C}_{\text {dimer }}\right)$ as a function of the total concentration $\left(\mathrm{C}_{\text {total }}\right)$ can be calculated based on the following equations.

$$
\begin{aligned}
& \text { Kagg }=\text { Cdimer } / C^{2} \text { monomer } \\
& \text { Ctotal }=\text { Cmonomer }+ \text { Cdimer }
\end{aligned}
$$

Assuming that a dimer only yields two electrons (only one monomer active with $\mathrm{n}=$ 2 , or only 1 electron per monomer), one may estimate the effective number of electrons as a function of total concentration based on the following equation:

$$
\text { neff }=2(\text { Cmonomer }+ \text { Cdimer }) / \text { Ctotal }
$$

Using Equation (3) and the obtained aggregation constant, the effective number of electrons was computed for the three compounds (6, 20, and 21) and shown in Figure 11. The impact of the aggregation on the effective number of electrons and the effectiveness of charged side-groups for reducing this problem are illustrated in Figure 11.

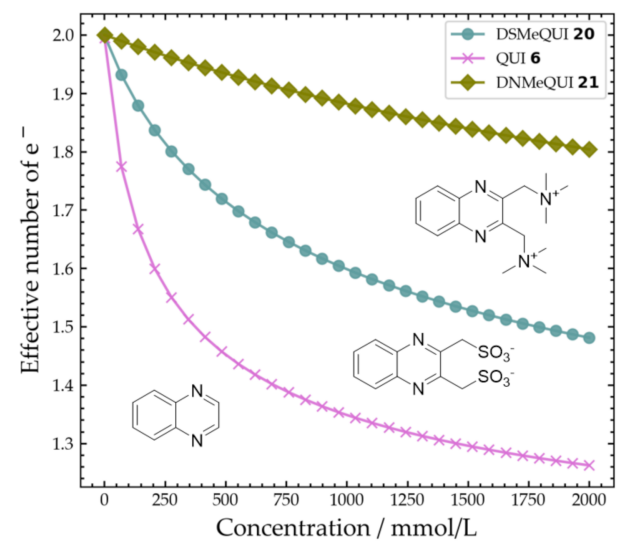

Figure 11. Effective number of electrons $\left(\mathrm{e}^{-}\right)$predicted as a function of the total concentration of the monomer for the three different quinoxalines $(6,20$, and 21$)$. The predictions are made based on Equations (2) and (3) and obtained aggregation constants.

\section{Discussion}

Organic molecules present a possibility of use as energy materials in aqueous organic RFB. In this study, we focused on the effect of different functional groups on aromatic 1,4-diaza molecules.

Firstly, it was shown that electron-withdrawing groups increased the potential of the molecule, while electron donating tended to decrease it. The position of the functional 
group relative to the active redox center (the pyrazine ring) played a major role as well, as the closer it was, the stronger the effect. Additionally, multiple charged substituent groups (carboxylate) on the pyrazine ring had a strong influence on the heterogeneous electron transfer kinetics, evident from the increased peak splitting. Degradation pathways can be hindered with the correct placement of functional groups, as seen in the case of DSMeQUI 20 compared to QUI 6. Thus, it is of great importance to investigate and map different degradation processes that can occur to be able to design highly durable compounds. We also identified two degradation products present in electrochemically cycled QUI 6-containing electrolyte with a $\mathrm{pH}=13$, corresponding to quinoxaline-2-ol (8a) and 1,2,3,4-tetrahydroquinoxaline (10b).

Secondly, $\mathrm{pH}$ plays a major role both with respect to the heterogeneous rate constant (kinetics) and on the degradation.

Thirdly, the dimerization of relatively planar aromatic organic compounds is a phenomenon that affects the effective number of electrons and thus the accessible capacity of a flow battery. $\pi$-stacking was identified as the most likely interaction driving the dimerization. The degree of dimerization was influenced by the functional groups attached due to coulomb repulsion and steric hindrance. ${ }^{1} \mathrm{H}-\mathrm{NMR}$ was employed to calculate the dimerization constant, similar to previous works [23,24]. Finally, based on the dimerization constant, we were able to estimate the effective number of electrons for the three model compounds, namely QUI 6, DSMeQUI 20, and DNMeQUI 21. At a concentration of $2 \mathrm{M}$ (which is reasonable for flow cell battery application) the effective numbers of electrons for QUI 6, DSMeQUI 20, and DNMeQUI 21 were approximately 1.26, 1.48, and 1.8, respectively. These values correspond to $63 \%, 74 \%$, and $90 \%$, respectively, of the expected theoretical capacity. In this context, we note that we observed significantly lower capacities than predicted by the dimerization equilibrium constant and our assumptions about the electroactivity of the monomers ( $\mathrm{n}=1$ per monomer) that make up the dimers. This is possibly a consequence of degradation, which was relatively rapid even though substitution at the 2,3-position appeared to be an efficient strategy to prevent or slow down addition of water to the pyrazine ring. In the case of QUI 6, after testing (5 cycles, $\mathrm{pH} 13$ ) we observed mainly QUI 6 in solution (See Figure S10), while the capacity was nearly zero at the end of the test. Significant cross-over was detected for QUI 6, but as it cannot explain the whole capacity fade, it indicates that another irreversible reaction may be causing an imbalance in the cell. Future work is aimed at identifying the degradation products of the protected molecule DSMeQUI 20 and at determining to what extent other side-reactions are contributing to the capacity fade observed in such alkaline quinoxaline-based flow batteries.

\section{Materials and Methods}

The current work focused on the electrochemical behavior of substituted pyrazines and quinoxalines under aqueous buffered and unbuffered solutions. Pyrazine 1,2-methylpyrazine 10, 2,5-dimethylpyrazine 11, 2,3,5,6-tetramethylpyrazine 12, pyrazine-2-carboxylic acid 13, pyrazine-2,5-dicarboxylic acid dihydrate 14, QUI 6, quinoxaline-6-carboxylic acid 19, 2-methylquinoxaline 16, 5-methylquinoxaline 17, and 3 hydroxyquinoxaline-2-carboxylic acid 18 were purchased from Sigma-Aldrich (Søborg, Denmark) and used without any further purification, while pyrazine-2,3,5,6-tetracarboxylic 15 acid was synthesized in-house. Sodium quinoxaline-2,3-bismethylsulfonate (DSMeQUI) was synthesized in house by an SN2 type reaction on 2,3 bis(bromomethyl)quinoxaline. The unbuffered solutions were based on $\mathrm{KCl}, \mathrm{KOH}$, and $37 \% \mathrm{HCl}$ as electrolytes, while for the buffered solutions the Britton-Robinson universal buffer was used and adjusted to the desired $\mathrm{pH}$ by the addition of solid $\mathrm{KOH}$.

Cyclic voltammetry (CV) and steady state rotating (ring) disk voltammetry (RRDV) were conducted with a $\mathrm{CH} 760 \mathrm{E}$ workstation potentiostat ( $\mathrm{CH}$ instruments, Inc., Dallas, TX, USA). In both cases, a three electrode configuration was used with the working electrode (WE), being glassy carbon in CV, and a rotating ring disk electrode consisted of glassy carbon (disk) and gold (ring) in RRDV. The counter and reference electrodes in both cases 
were a coiled platinum wire and an $\mathrm{Ag} / \mathrm{AgCl}(3 \mathrm{M} \mathrm{NaCl})$ electrode, respectively. Battery cycling took place with a Biologic SP-300 potentiostat (Biologic, Seyssinet-Pariset, France). Before cycling, the solution were degassed with Ar to remove dissolved $\mathrm{O}_{2}$. Afterwards, Ar was blown over the solution to mitigate further $\mathrm{O}_{2}$ ingress.

Nuclear magnetic resonance (NMR) analyses were conducted using a Spinsolve 80 benchtop NMR spectrometer (Magritek, Aachen, Germany). For the titration studies, the samples were analyzed with the conditions reported in the Supplementary Materials.

Supplementary Materials: The following are available, Synthetic procedures, chemical analysis, and single flow cell test data are available in the supporting information. Figures S1-S10, Schemes S1-S3 [26-28].

Author Contributions: A.P.-K.: Conceptualization, Methodology, Formal Analysis, Investigation, Data curation, Writing — Original draft, Writing—Review and Editing, Visualization, Software. V.B.: Conceptualization, Methodology, Validation, Formal Analysis, Investigation, Writing-Original draft, Writing—Review and Editing, Visualization. J.H.: Conceptualization, Methodology, Resources, Writing-Review and Editing, Supervision, Project administration, Funding acquisition. All authors have read and agreed to the published version of the manuscript.

Funding: This work was financially supported through investments by Innovation Fund Denmark via the Grand Solutions projects "ORBATS" file no. 7046-00018B and "DanFlow" file no. 9090-00059B.

Institutional Review Board Statement: Not applicable.

Informed Consent Statement: Not applicable.

Data Availability Statement: The data for of the voltammograms can be found here https://doi. org/10.5281/zenodo.4670042. The NMR data can be provided upon request.

Conflicts of Interest: The authors declare no conflict of interest.

Sample Availability: Samples of the compounds DSMeQUI 20 and DNMeQUI 21 are available from the authors.

\section{References}

1. Yang, B.; Murali, A.; Nirmalchandar, A.; Jayathilake, B. A Durable, Inexpensive and Scalable Redox Flow Battery Based on Iron Sulfate and Anthraquinone Disulfonic. J. Electrochem. Soc. 2020. [CrossRef]

2. Zhang, C.; Niu, Z.; Peng, S.; Ding, Y.; Zhang, L.; Guo, X.; Zhao, Y.; Yu, G. Phenothiazine-Based Organic Catholyte for HighCapacity and Long-Life Aqueous Redox Flow Batteries. Adv. Mater. 2019, 31, 1-8. [CrossRef] [PubMed]

3. Brushett, F.R.; Aziz, M.J.; Rodby, K.E. On Lifetime and Cost of Redox-Active Organics for Aqueous Flow Batteries. ACS Energy Lett. 2020, 5, 879-884. [CrossRef]

4. Wu, M.; Jing, Y.; Wong, A.A.; Fell, E.M.; Jin, S.; Tang, Z.; Gordon, R.G.; Aziz, M.J. Extremely Stable Anthraquinone Negolytes Synthesized from Common Precursors. Chem 2020. [CrossRef]

5. Ji, Y.; Goulet, M.A.; Pollack, D.A.; Kwabi, D.G.; Jin, S.; De Porcellinis, D.; Kerr, E.F.; Gordon, R.G.; Aziz, M.J. A PhosphonateFunctionalized Quinone Redox Flow Battery at Near-Neutral pH with Record Capacity Retention Rate. Adv. Energy Mater. 2019, 9, 1-7. [CrossRef]

6. Quan, M.; Sanchez, D.; Wasylkiw, M.F.; Smith, D.K. Voltammetry of quinones in unbuffered aqueous solution: Reassessing the roles of proton transfer and hydrogen bonding in the aqueous electrochemistry of quinones. J. Am. Chem. Soc. 2007, 129, 12847-12856. [CrossRef]

7. Hofmann, J.D.; Schmalisch, S.; Schwan, S.; Hong, L.; Wegner, H.A.; Mollenhauer, D.; Janek, J.; Schröder, D. Tailoring Dihydroxyphthalazines to Enable Their Stable and Efficient Use in the Catholyte of Aqueous Redox Flow Batteries. Chem. Mater. 2020. [CrossRef]

8. Milshtein, J.D.; Su, L.; Liou, C.; Badel, A.F.; Brushett, F.R. Voltammetry study of quinoxaline in aqueous electrolytes. Electrochim. Acta 2015, 180, 695-704. [CrossRef]

9. Hollas, A.; Wei, X.; Murugesan, V.; Nie, Z.; Li, B.; Reed, D.; Liu, J.; Sprenkle, V.; Wang, W. A biomimetic high-capacity phenazine-based anolyte for aqueous organic redox flow batteries. Nat. Energy 2018, 3, 508-514. [CrossRef]

10. Lin, K.; Gómez-Bombarelli, R.; Beh, E.S.; Tong, L.; Chen, Q.; Valle, A.; Aspuru-Guzik, A.; Aziz, M.J.; Gordon, R.G. A redox-flow battery with an alloxazine-based organic electrolyte. Nat. Energy 2016, 1, 1-8. [CrossRef]

11. Kwon, G.; Lee, S.; Hwang, J.; Ku, K.; Kwon, G.; Lee, S.; Hwang, J.; Shim, H.; Lee, B.; Lee, M.H. Multi-redox Molecule for High-Energy Redox Flow Batteries Multi-redox Molecule for High-Energy Redox Flow Batteries. Joule 2018, 1-12. [CrossRef]

12. Dai, G.; He, Y.; Niu, Z.; He, P.; Zhang, C.; Zhao, Y.; Zhang, X.; Zhou, H. A Dual-Ion Organic Symmetric Battery Constructed from Phenazine-Based Artificial Bipolar Molecules. Angew. Chemie Int. Ed. 2019. [CrossRef] 
13. Clayden, J.; Greeves, N.; Warren, S. Organic Chemistry, 2nd ed.; Oxford University Press: Oxford, UK, 2012; ISBN 978-0-19-927029-3.

14. Klatt, L.N.; Rouseff, R.L. Electrochemical Reduction of Pyrazine in Aqueous Media. J. Am. Chem. Soc. 1972, 94, 7295-7304. [CrossRef]

15. Aleksic, M.; Pantic, J.; Kapetanovic, V. Evaluation of kinetic parameters and redox mechanism of quinoxaline at glassy carbon electrode. Facta Univ. Ser. Phys. Chem. Technol. 2014, 12, 55-63. [CrossRef]

16. Swartz, J.; Anson, F.C. A comparison of the staircase voltammetric and polarographic responses of pyrazine and several substituted pyrazines in aqueous acid. J. Electroanal. Chem. Interfacial Electrochem. 1980, 114, 117-128. [CrossRef]

17. Rupar, J.; Aleksić, M.M.; Nikolić, K.; Popović-Nikolić, M.R. Comparative electrochemical studies of kinetic and thermodynamic parameters of Quinoxaline and Brimonidine redox process. Electrochim. Acta 2018, 271, 220-231. [CrossRef]

18. Fischer, O.; Thuy, T.H. Beitrag zum elektrochemischen Verhalten des Chinoxalins im wässrigen Medium. Collect. Czechoslov. Chem. Commun. 1976. [CrossRef]

19. Ding, Y.; Zhang, C.; Zhang, L.; Zhou, Y.; Yu, G. Molecular engineering of organic electroactive materials for redox flow batteries. Chem. Soc. Rev. 2018, 47, 69-103. [CrossRef]

20. Costentin, C.; Robert, M.; Savéant, J.M. Electrochemical approach to the mechanistic study of proton-coupled electron transfer. Chem. Rev. 2010, 110, 2145-2179. [CrossRef]

21. Evans, D.H. One-electron and two-electron transfers in electrochemistry and homogeneous solution reactions. Chem. Rev. 2008, 108, 2113-2144. [CrossRef]

22. Pang, S.; Wang, X.; Wang, P.; Ji, Y. Biomimetic Amino Acid Functionalized Phenazine Flow Batteries with Long Lifetime at Near-Neutral pH. Angew. Chemie Int. Ed. 2020. [CrossRef]

23. Carney, T.J.; Collins, S.J.; Moore, J.S.; Brushett, F.R. Concentration-Dependent Dimerization of Anthraquinone Disulfonic Acid and Its Impact on Charge Storage. Chem. Mater. 2017, 29, 4801-4810. [CrossRef]

24. Wiberg, C.; Carney, T.J.; Brushett, F.; Ahlberg, E.; Wang, E. Dimerization of 9,10-anthraquinone-2,7-Disulfonic acid (AQDS). Electrochim. Acta 2019, 317, 478-485. [CrossRef]

25. Horman, I.; Dreux, B. Estimation of Dimerisation Constants from Complexatin-Induced Displacements of 1H-NMR Chemical Shifts: Dimerisation of Caffeine. Helv. Chim. Acta 1984, 67, 754-764. [CrossRef]

26. Brauman, J.I.; Pandell, A.J. Mechanism of Permanganate Oxidation of Tertiary Hydrogen to Hydroxy1a. J. Am. Chem. Soc. 1970, 92, 329-335. [CrossRef]

27. Parvez, M.M.; Haraguchi, N.; Itsuno, S. Molecular design of chiral quaternary ammonium polymers for asymmetric catalysis applications. Org. Biomol. Chem. 2012, 10, 2870-2877. [CrossRef]

28. Schwiderski, R.L.; Rasmussen, S.C. Synthesis and characterization of thieno [3,4-b]pyrazine-based terthienyls: Tunable precursors for low band gap conjugated materials. J. Org. Chem. 2013, 78, 5453-5462. [CrossRef] 